\title{
Reproductive parameters in Holstein dairy cows treated with three resynchronization methods
}

\author{
Nasroallah Moradi kor ${ }^{1 *}$, Kaveh Mohammadi Khanghah ${ }^{2}$, Mona Ghasemi ${ }^{2}$ \\ ${ }^{I}$ Department of Animal Science, Islamic Azad University, Baft Branch, Baft, Iran, ${ }^{2}$ Department of Animal \\ Science, Razi University of Agricultural Sciences and Natural Resources, Kermanshah, Iran
}

\begin{abstract}
The objective of the present study was to determine the reproductive parameters in Holstein cows treated by different hormonal protocols during insemination and postpartum periods. The 114 dairy cows (multiparous) with BCS between 2.75 and 3 were divided into 3 groups in a completely randomized design. 38 cows were treated by Heatsynch method $+e C G\left(M_{1}\right), 38$ cows received Ovsynch $+C I D R\left(M_{2}\right)$ and 38 cows were subjected to the Heatsynch method $\left(M_{3}\right)$. Blood samples were taken to determine progesterone plasma contents in 14, 21 and 24 days after first insemination. Results showed that treatment with $M_{2}$ protocol significantly decreased days to first service and conception rate in the cows $(P<0.05)$. First service conception rate in cows treated with $M_{1}$ protocol was higher $(P<0.05)$ compared to $M_{2}$ and $M 3$ protocol. Pregnancy rate in $M_{I}$ was significantly higher than that of the other groups $(P \leq 0.05)$. This difference could be due to equine chorionic gonadotrophin (eCG) which could have an effective function on ovulation, fertilization and embryo's vitality. Plasma progesterone levels of pregnant cows were higher than that of nonpregnants cows regardless the type of resynchronization protocols $(P \leq 0.05)$. However, activation of ovaries, reinitiate estrous cycle and accordance between estrous and ovulation were increased when dairy cows subjected to the Heatsynch $+e C G$ method $\left(M_{1}\right)$. Thus, $M_{2}$ protocol is recommended for primiparous but not for multiparous cows, and $T_{3}$ protocol is not recommended for synchronization.
\end{abstract}

Key words : Progesterone, Reproductive indices, CIDR, Dairy cattle, eCG

\section{I.Introduction}

Lactating dairy cows with high genetic merit and outstanding milk production are likely to be more vulnerable to fertility problems, such as lower AI conception rates, weaker expression of estrus, and greater embryonic loss after insemination than lower producing cows [18]. Reproductive efficiency in dairy herds increases by inseminating all the cows shortly after the end of the voluntary waiting period, obtaining high pregnancy rate to first service, enhancing embryonic and fetal survival, and detecting and re-inseminating nonpregnant cows. Ultrasonography enables early pregnancy diagnosis and detection of non-pregnant cows, which can be subjected to resynchronization of ovulation and timed AI (TAI) to minimize the problem of low estrus detection [24]. When estrus was synchronized and AI was scheduled after detected estrus in earlier studies, fertility was greater than when AI was made at fixed times after synchronization without regard to detected estrus $[4,19,16]$. Poorer fertility after timed AI (TAI) often was attributed to insufficient synchrony of estrus and ovulation to allow appropriate timing of AI relative to ovulation [8]. Deficiencies in luteal function [6], either before or after insemination, are associated with reduced fertility in beef [21] and dairy cattle [10]. In addition, concentrations of progesterone ( $\mathrm{P} 4)$ in blood 34 to $48 \mathrm{~h}$ before the preovulatory surge of LH were greater in cows that conceived compared with those that failed to conceive [7]. Thus, the magnitude of P4 concentrations before estrus may be associated with factors that increase the probability of conception. Blood concentrations of P4 during the luteal phase before insemination are associated positively with conception rate $[9,7,12,10,26,27]$. Increased pregnancy rate was reported after intra vaginal inserts containing P4 were applied to cows that were synchronized with $\mathrm{PGF}_{2 \alpha}$ [33]. Therefore, reproductive performance of cows receiving the Ovsynch protocol may be improved if $\mathrm{P}_{4}$ is administered during the $7 \mathrm{~d}$ between the first $\mathrm{GnRH}$ and the only $\mathrm{PGF}_{2 \alpha}$ injections. Progesterone should prevent premature estrus and ovulation during the period in which spontaneous luteolysis may occur in small percentages of cows whose dominant follicles are not responsive to the first GnRH injection [30, 25, 28, 31, 32]. Protocols for synchronization of ovulation and TAI, such as Ovsynch (GnRH on day 0, PGF 2a on day 7, GnRH on day 9 and TAI 16 h later; [25, 1997] and Heatsynch (GnRH on day 0, PGF 2a on day 7, ECP on day 8, and TAI on day 10; [22], insure that all cows are inseminated and generate acceptable pregnancy rates in lactating dairy cows. Since the stage of the estrous cycle is known to affect the response to these protocols [31, 20], a presynch program was developed that allows initiation of Ovsynch in the early- to mid- luteal phase of the estrous cycle, improving pregnancy rate to first service in cyclic cows [20]. Protocols for resynchronization of estrus that considered the stage of the estrous cycle have been applied after detection of non-pregnant cows by per rectum palpation of 
Reproductive parameters in holstein dairy cows treated with three resynchronization methods

the uterus and assignment of protocols based on the presence or absence of a CL [1]. Another approach for resynchronization after non-pregnancy diagnosis by ultrasonography was either to initiate the Ovsynch protocol 7 days before ultrasonography or to take advantage of a natural resynchronization after previous service with application of shortened protocols that used $\mathrm{PGF}_{2 \mathrm{a}}$ to induce luteolysis and then GnRH [29] or ECP [3] to induce ovulation. An alternative is to consider the stage of the estrous cycle at the time of initiation of the resynchronization protocol by evaluating ovarian structures and uterine characteristics at the time of a nonpregnancy diagnosis. Determination of the stage of the estrous cycle can be done using per rectum examination and ultrasonography [24] of the genital tract. The objective of this study was to effects of different resynchronization methods on reproductive indices in lactating dairy cows.

\section{Materials and methods}

This study was performed at a private dairy farm housing consisting 300 Holstein Friesian milking cows with cooperation Rezvan Agriculture junior college located in Kerman province (latitude $25^{\circ} 55^{\prime} \mathrm{N}$, longitude $53^{\circ} 26^{\prime} \mathrm{E}$, altitude $1755 \mathrm{~m}$ ) in Iran. Cows were housed in free stall barns and dry lots and fed a total mixed ration (TMR) thrice daily to meet or exceed requirements for lactating cows. Cows with reproductive abnormalities (i.e., metritis, pyometra, uterine or ovarian adhesions) were not included in the study. The 114 dairy cows (second lactation) with BCS between 2.75 and 3 were divided into 3 groups in a completely randomized design. 38 cows were treated by Heatsynch method + eCG (T1), 38 cows received Ovsynch + CIDR (T2) and 38 cows were subjected to the Heatsynch method (T3). Group $\mathbf{M}_{\mathbf{1}}(\mathbf{n}=\mathbf{3 8})$ : Cows in the Heatsynch+ eCG group received $100 \mathrm{mg}$ im of GnRH and 200 (IU) eCG on day $0,25 \mathrm{mg}$ im of PGF2 $\alpha$ on day 7, $1 \mathrm{mg}$ im of ECP $(0.5 \mathrm{~mL}$ of ECP1 sterile solution; Pfizer Animal Health) on day 8, and TAI $48 \mathrm{~h}$ later (day10).

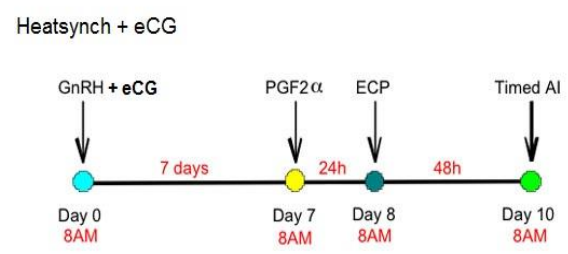

Fig. 1. Heatsynch $+\mathrm{eCG}$ protocol.

Group $\mathbf{M}_{2}(\mathbf{n}=38)$ : Cows in the Ovsynch + CIDR group received $100 \mathrm{mg}$ im of GnRH $(2 \mathrm{~mL}$ of Cystorelin1; Merial Ltd., Iselin, NJ, USA) on day $0,25 \mathrm{mg}$ im of PGF2 $\alpha$ ( $5 \mathrm{~mL}$ of Lutalyse1 sterile solution; Pfizer Animal Health, New York, USA) on day 7, $100 \mathrm{mg}$ im of GnRH on day 9, and TAI $16 \mathrm{~h}$ later (day 10).

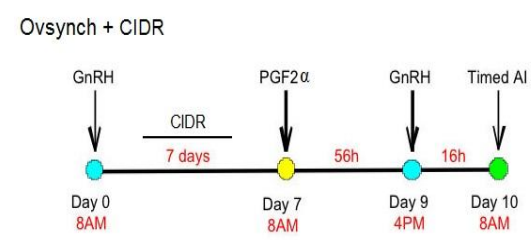

Fig. 2. Ovsynch + CIDR protocol.

Group $\mathbf{M}_{3}(\mathbf{n}=\mathbf{3 8}$ ): Cows in the Heatsynch group received $100 \mathrm{mg}$ im of GnRH on day $0,25 \mathrm{mg}$ im of PGF 2a on day 7, $1 \mathrm{mg}$ im of ECP( $0.5 \mathrm{~mL}$ of ECP1 sterile solution; Pfizer Animal Health) on day 8, and TAI 48 $\mathrm{h}$ later (day10).

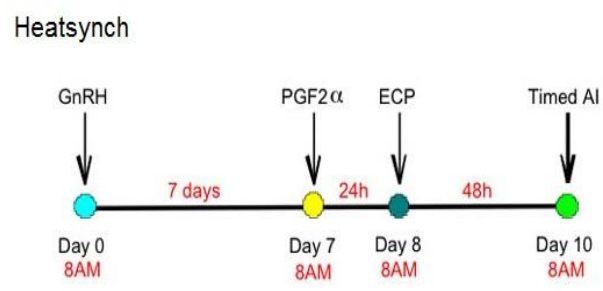

Fig. 3. Heatsynch protocol.

In days 14, 21 and 24 after insemination, blood samples were taken from jugular vein in 10-ml vacuum tubes (venoject) for pregnancy diagnosis. Serum was recovered by centrifugation (10 minutes at $3000 \mathrm{rpm})$ and stored at $-20^{\circ} \mathrm{C}$ until assayed for Serum progesterone concentrations using commercially available ELISA kit (Demeditec Diagnostics GmbH, Kiel, Germany). The reproductive parameters recorded. Data was analysed 
Reproductive parameters in holstein dairy cows treated with three resynchronization methods

using the General Linear Model (GLM) procedures of statistical analysis system (SAS) by compeletly randomize design and the means were compared using Duncan's multiple range test.

\section{III.Results and Discussion}

The results of reproductive parameters are summarized in (Table 1). The number of $\mathrm{S} / \mathrm{C}$ for pregnant cows was lower for cows treated with $\mathrm{M}_{2}$ protocol compared to $\mathrm{M}_{1}$ and $\mathrm{M}_{3}$ protocols respectively; $P<0.01$ ). No difference $(P>0.05)$ was observed for Service/Conception $(\mathrm{S} / \mathrm{C})$ between the cows with $\mathrm{M}_{1}, \mathrm{M} 2$ and $\mathrm{M}_{3}$ protocols. First service conception rate on Day 30 for cows in the $\mathrm{M}_{1}$ protocol tended to be higher than those for cows in the $\mathrm{M}_{2}$ and $\mathrm{M}_{3}$ protocols. However, there was a significantly difference $(\mathrm{P}<0.05)$ for FSCR amongst $\mathrm{M}_{1}$ with $\mathrm{M}_{2}$ and $\mathrm{M}_{3}$ protocols.

Table 1. The effect of three resynchronization methods on reproductive parameters of dairy cows.

\begin{tabular}{|c|c|c|c|c|c|c|}
\hline Parameter(s) & \multicolumn{2}{|c|}{ Heatsynch + eCG } & \multicolumn{2}{|c|}{ Ovsynch + CIDR } & \multicolumn{2}{|c|}{ Heatsynch } \\
\hline & ${ }^{5} \mathrm{RS}$ & ${ }^{6} \mathrm{OS}$ & $\mathrm{RS}$ & OS & $\mathrm{RS}$ & OS \\
\hline${ }^{1} \mathrm{FSCR}(\%)$ & $\% 45$ & $\% 55^{*}$ & $\% 57$ & $\% 43$ & $\% 67$ & $\% 33$ \\
\hline${ }^{2} \operatorname{SSCR}(\%)$ & $\% 35$ & $\% 65$ & $32 \%$ & $68 \%$ & $\% 50$ & $\% 50$ \\
\hline${ }^{3} \operatorname{TSCR}(\%)$ & $\% 30$ & $\% 70$ & $\% 27$ & $\% 73^{*}$ & $\% 44$ & $\% 56$ \\
\hline${ }^{4} \mathrm{~S} / \mathrm{C}$ & \multicolumn{2}{|c|}{$2 / 06 \pm 0.24$} & \multicolumn{2}{|c|}{$1 / 98 \pm 0.19$} & \multicolumn{2}{|c|}{$2 / 33 \pm 0.25$} \\
\hline Open days & \multicolumn{2}{|c|}{104} & \multicolumn{2}{|c|}{96} & \multicolumn{2}{|c|}{121} \\
\hline
\end{tabular}

Synchronization of oestrus using prostaglandin programs in lactating cows is an established technique for reducing the post partum interval to first insemination [15, 23]. The results from this study showed that treatment with $\mathrm{PGF}_{2 \alpha}$ on Day 15 post partum has the potential to reduce days to conception and number of $\mathrm{S} / \mathrm{C}$ only in cows that were treated with $\mathrm{M}_{2}$ protocol (Table 1). These results are consistent with observations reported by Benmrad \& Stevenson, [2] and Young et al. [34], who indicated that a single intramuscular injection of $\mathrm{PGF}_{2 \alpha}$ in the early post partum period reduced the post partum interval to conception. However, our results are in contrast with the results of López-Gatius and Camón-Urgel, [17], who reported that interval from calving to conception, number of services per conception and percentage of cows pregnant to first service were not influenced by treatment of $\mathrm{PGF}_{2 \alpha}$ on Day 14 post partum. Our results showed that treatment with $\mathrm{PGF}_{2 \alpha}$ on Day 15 post partum significantly improved FSCR only in cows were treated with $\mathrm{M}_{1}$ protocol (Table 1). Results of this experiment revealed that Plasma progesterone in first group was significantly different than that of the other groups (Fig. 4).

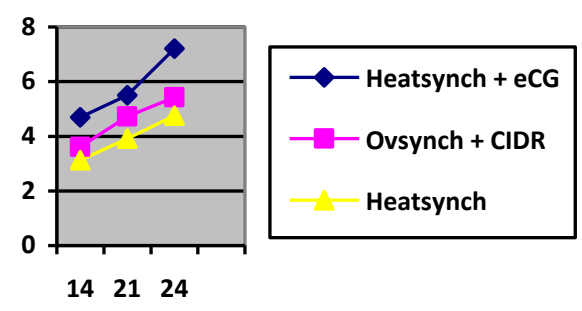

Fig.4. Mean blood progesterone concentration in days after AI.

Our results are in agreement with those of Young et al., [34] who reported that cows treated with $\mathrm{PGF}_{2 \alpha}$ between 4 and 28 days post partum, irrespective of post partum disease and/or abnormal calving, had a $25 \%$ higher first service conception rate than controls. Kasimanickam et al. [14] evaluated the effect of a single treatment with $\mathrm{PGF}_{2 \alpha}$ on fertility and reported an overall increase in pregnancy to first AI. DeJarnette and Marshall [5] found that two $\mathrm{PGF}_{2 \alpha}$ treatments can be advantageous for secondiparous. In an attempt to hasten uterine involution and thus shorten the interval from parturition to estrus, exogenous $\mathrm{PGF}_{2 \alpha}$ or its synthetic analogs have been administered early post partum (usually as a single dose, i.m.) in both dairy and beef cows with variable results [17]. However, there are conflicting reports on the effectiveness of exogenous PGF $_{2 \alpha}$ to increase the rate of uterine involution, cause evacuation of bacterial contamination from the uterus, and subsequently improve conception rate [14]. These reports examined the use of $\mathrm{PGF}_{2 \alpha}$ on either one or two occasions between 12 and 40 days post partum, without regard to the presence of a functional corpus luteum. It has been shown that treatment with $\mathrm{PGF}_{2 \alpha}$ can increase uterine $\mathrm{PGF}_{2 \alpha}$ and luteal leukotriene $\mathrm{B} 4\left(\mathrm{LT}_{\mathrm{B} 4}\right)$ secretion, and that $\mathrm{LT}_{\mathrm{B} 4}$ can enhance chemotaxis, random migration and antibody-independent cell-mediated 
Reproductive parameters in holstein dairy cows treated with three resynchronization methods cytotoxicity [11]. In the present study, administration of GnRH on Day 23 post-AI increased the days to conception and the number of S/C and decreased FSCR in cows treated with $M_{1}$ compared to $M_{2}$ protocol (Table 1). Several studies have investigated the effect of treatment with GnRH or equine chorionic gonadotropin (eCG) after insemination to improve fertility by inducing ovulation and forming an accessory corpus luteum [13]. Corpus luteum development results in secretion of P4, which influences embryo development, interferon- $\tau$ production, and inhibition of the luteolytic cascade. Administration of GnRH on days 22-23 after a previous AI should induce ovulation in the majority of cows and result in formation of a CL and synchronization of an ovarian follicular wave. Observations reported by Chebel et al. [3], indicated that the administration of GnRH on Day 21 after AI to lactating dairy cows of unknown pregnancy status, did not affect pre-enrollment pregnancy rates determined on Days 28 and 42 after insemination.

\section{Conclusion}

It was concluded from the findings that treatment with $\mathrm{PGF}_{2 \alpha}$ on Day 15 post partum had a beneficial effect on the reproductive performance in cows were treated with $\mathrm{M}_{1}$ and $\mathrm{M} 2$ protocol. Furthermore, administration of a GnRH agonist on Day 23 after AI did not improve reproductive performance for cows receiving first post partum TAI after Heatsynch protocol.

\section{Acknowledgments}

The authors would like to thanks Mr. Mehrdad Frahbakhsh, dairy farm manager and also to have special gratitude to Mr. Ebrahim esfandiar pour member scientific of Agriculture Rezvan junior college for his kind cooperation.

\section{References}

[1] Bartolome JA, Sheerı'n P, Luznar S, Mele'ndez P, Kelbert D, Risco CA, Thatcher WW., 2002. Conception rate in lactating dairy cows using Ovsynch after presynchronization with prostaglandin F2a (PGF 2a) or gonadotropin releasing hormone (GnRH). The Bovine Practitioner;36:35-9.16.

[2] Benmrad, M. \& Stevenson, J. S., 1985. Gonadotrophin releasing hormone and prostaglandin F2 $\alpha$ for post partum dairy cows; oestrus, ovulation and fertility traits. Journal of Dairy Science 69, 800-11.

[3] Chebel R, Santos JEP, Cerri RLA, Juchem S, Galvao KN, Thatcher WW., 2003. Effect of resynchronization with GnRH on day 21 after artificial insemination on pregnancy rate and pregnancy loss in lactating dairy cows. Theriogenology;60:1389-99.

[4] Dailey, R. A., R. E. James, E. K. Inskeep, and S. P. Washburn. 1983. Synchronization of estrus in dairy heifers with prostaglandin $F_{2 \alpha}$ with or without estradiol benzoate. J. Dairy Sci. 66:881-886.

[5] DeJarnette JM, Marshall CE., 2003. Effects of pre-synchronization using combinations PGF2a, and (or) GnRH on pregnancy rates of Ovsynch- and Cosynch-treated lactating Holstein cows. Anim Reprod Sci;77:51-60.

[6] Dizerega, G. S., and G. D. Hodgen. 1981. Luteal phase dysfunction infertility: A sequel to aberrant folliculogenesis. Fertil. Steril. 35:489-499.

[7] Erb, R. E., H. A. Garverick, R. D. Randel, B. L. Brown, and C. J. Callahan. 1976. Profiles of reproductive hormones associated with fertile and non-fertile inseminations of dairy cows. Theriogenology 5:227-242.

[8] Fogwell, R. L., B. M. Kanyima, A. Villa-Godoy, W. J. Enright, and J. J. Ireland. 1986. Enhanced precision of estrus and luteinizing hormone after progesterone and prostaglandin in heifers. J. Dairy Sci. 69:2179-2185.

[9] Folman, Y., M. Kaim, Z. Herz, and M. Rosenberg. 1990. Comparison of methods for the synchronization of estrous cycles in dairy cows. 2. Effects of progesterone and parity on conception. J. Dairy Sci. 73:2817-2825.

[10] Fonseca, F. A., J. H. Britt, B. T. McDaniel, J. C. Wilk, and A. H. Rakes. 1983. Reproductive traits of Holsteins and Jerseys. Effects of age, milk yield, and clinical abnormalities on involution of cervix and uterus, ovulation, estrous cycles, detection of estrus, conception rate, and days open. J. Dairy Sci. 66:1128-1147.

[11] Hoedemaker M, Lund LA, Wagner WC., 1992. Influence of arachidonic acid metabolites and steroids on function of bovine polymorphonuclear neutrophils. Am J Vet Res;53:1534-1539.

[12] Holness, D. H., G. W. Sprowson, C. Sheward, and A. Geel. 1981. Studies on plasma progesterone concentrations and fertility in Friesland dairy cows during the postpartum period. J. Agric. Sci. 97:649-654.

[13] Howard, J. M., R. Manzo, J. C. Dalton, F. Frago, and A. Ahmadzadeh. 2006. Conception rates and serum progesterone concentration in dairy cattle administered gonadotropin releasing hormone five days after artificial insemination. Anim. Reprod. Sci. 95(3-4):224-233.

[14] Kasimanickam, R., Duffield, T.E., Foster, R.A., Gartley, C.J., Leslie, K.E.,Walton, J.S., Johnson,W.H., 2005. The effect of a single administration of cephaprim or cloprostenol on the reproductive performance of dairy cows with sub clinical endometritis. Theriogenology 63, 818-830.

[15] Kristula, M., R. Bartholomew,D.Galligan, and C. Uhlinger. 1992. Effects of a prostaglandin F2 $\alpha$ synchronization program in lactating dairy cattle. J Dairy Sci. 75:2713-2718.

[16] Larson, L. L., and P. J. H. Ball. 1992. Regulation of estrous cycles in dairy cattle: A review. Theriogenology 38:255-267.

[17] López-Gatius, F. and Camón-Urgel, J. 1989. Reproductive Parameters in Dairy Cows with Normal Puerperium Treated with Prostaglandin F2 $\alpha$-Tham on Day 14 Postpartum. Reproduction in Domestic Animals, 24: 201-206.

[18] Lucy, M. C. 2001. Reproductive loss in high-producing dairy cattle: Where will it end? J. Dairy. Sci. 84:1277-1293.

[19] Lucy, M. C., J. S. Stevenson, and E. P. Call. 1986. Controlling first service and calving interval by prostaglandin F2 $\alpha$, gonadotropin releasing hormone, and timed insemination. J. Dairy Sci. 69:2186-2194.

[20] Moreira F, Orlandi C, Risco CA, Lopes F, Mattos R, Thatcher WW., 2001. Effects of presynchronization and bovine somatotropin on pregnancy rates to a timed artificial insemination protocol in lactating dairy cows. J. Dairy Sci;84:1646-59.

[21] Odde, K. G. 1990. A review of synchronization of estrus in postpartum cattle. J. Anim. Sci. 68:817-830.

[22] Pancarci SM, Jordan ER, Risco CA, Schouten MJ, Lopes FL, Moreira F, Thatcher WW., 2002. Use of estradiol cypionate in a pre-synchronized timed artificial insemination program for lactating dairy cattle. J Dairy Sci;85:122-31. 
[23] Pankowski JW, Galton DM, Erb HN, Guard CL, Grohn YT., 1995. Use of prostaglandin F2 $\alpha$, as a postpartum reproductive management tool for lactating dairy cows. J Dairy Sci; 78:1477-1488.

[24] Pierson RA, Ginther OJ., 1987. Ultrasonographic appearance of the bovine uterus during the estrous cycle. JAVMA;190:9951001.

[25] Pursley JR, Mee MO, Wiltbank MC., 1995. Synchronization of ovulation in dairy cows using PGF2a and GnRH. Theriogenology;44:915-23.

[26] Rosenberg, M., Z. Herz, M. Davidson, and Y. Folman. 1990a. Seasonal variation in postpartum plasma progesterone levels and conception in primiparous and multiparous dairy cows. J. Reprod. Fertil. 51:363-367.

[27] Rosenberg, M., M. Kaim, Z. Herz, and Y. Folman. 1990b. Comparison of methods for the synchronization of estrous cycles in dairy cows. 1. Effects on plasma progesterone and manifestation of estrus. J. Dairy Sci. 73:2807-2816.

[28] Roy, G. L., and H. Twagiramungu. 1999. Time interval between GnRH and prostaglandin injection influences the precision of estrus in synchronized cattle. Theriogenology 51:413. (Abstr.)

[29] Stevenson JS, Cartmill JA, Hensley BA, El-Zarkouny SZ., 2003. Conception rates of dairy cows following early not-pregnant diagnosis by utrasonography and subsequent treatments with shortened Ovsynch protocol. Theriogenology;60:475-83.

[30] Twagiramungu, H., L. A. Guilbault, J. Proulx, P. Villeneuve, and J. J. Dufour. 1992. Influence of an agonist of gonadotropinreleasing hormone (Buserelin) on estrus synchronization and fertility in beef cows. J. Anim. Sci. 70:1904-1910.

[31] Vasconcelos JLM, Silcox RW, Rosa GJM, Pursley JR, Wiltbank MC., 1999. Synchronization rate, size of the ovulatory follicle, and pregnancy rate after synchronization of ovulation beginning on different days of the estrous cycle in lactating dairy cows. Theriogenology;52:1067-78.

[32] Xu, Z. Z., and L. J. Burton. 2000. Estrous synchronization of lactating dairy cows with GnRH, progesterone, and prostaglandin $F_{2 \alpha}$. J. Dairy Sci. 83:471-476.

[33] Xu, Z. Z., L. J. Burton, and K. L. Macmillan. 1997. Reproductive performance of lactating dairy cows following estrus synchronization regimens with $\mathrm{PGF}_{2 \alpha}$ and progesterone. Theriogenology 47:687-701.

[34] Young IM, Anderson DB, Plenderlieth RWJ., 1984. Increased conception rate in dairy cows after early postpartum administration of prostaglandin F2a Tham. Vet Rec;115:429-31. 